\title{
PAKKADES.ID UNTUK MENDUKUNG PHYSICAL DISTANCING SAAT MUSYAWARAH ANGGARAN PEMBANGUNAN DESA SEBAGAI UPAYA MENGHADAPI PANDEMI
}

\author{
Trias Bratakusuma \\ Universitas Amikom Purwokerto \\ brata@amikompurwokerto.ac.id
}

\begin{abstract}
Nowadays, although the pageraji village government has implemented e-government but more to increase services through the elimination of the old and complicated bureaukasi structure. In this case more information systems are used to speed up and automate processes. There is no information system yet focused on supporting the decision process. Pakkades.id is a type of information system intended to facilitate budgeting mechanisms. In the process of drafting village development budgets, community participation or aspirations are urgently needed. However, there are often obstacles to getting aspirations from the community because the mechanism that is implemented now only through deliberations implemented one day, this will narrow the reach. Therefore, with the implementation of Pakkades.id which is the result of the study authors of the Funding Ristek Dikti 2019 is expected to efficiency and effectively process decision making through the process of capturing the aspirations of the community better.
\end{abstract}

Keywords: Pakkades.id, Budget, Village Development, E-Goverment

\begin{abstract}
Abstrak
Saat ini walaupun pemerintah desa Pageraji telah menerapkan e-government namun lebih banyak untuk peningkatkan pelayanan melalui penghapusan struktur birokasi yang lama dan rumit. Dalam hal ini sistem informasi lebih banyak digunakan untuk mempercepat dan otomatisasi proses. Belum ada sistem informasi yang berfokus untuk mendukung proses keputusan. Pakkades.id adalah salah satu tipe sistem informasi yang ditujukan untuk memfasilitasi mekanisme penganggaran. Dalam proses penyusunan anggaran pembangunan desa, peran serta atau aspirasi masyarakat sangat dibutuhkan. Namun demikian sering kali terdapat kendala untuk mendapatkan aspirasi dari masyarakat karena mekanisme yang dijalankan sekarang hanya melalui musyawarah yang dilaksanakan satu hari, hal ini akan mempersempit jangkauan. Untuk itu dengan implementasi Pakkades.id ini yang merupakan hasil penelitian penulis dari Pendanaan Ristek Dikti 2019 diharapkan dapat mengefisiensikan dan mengefektifkan proses pengambilan keputusan melalui proses menangkap aspirasi masyarakat yang lebih baik
\end{abstract}

Kata Kunci: Pakkades.id, Anggaran, Pembangunan Desa, E-Goverment

\begin{tabular}{|l|l|l|} 
Submitted: $2020-09-24$ & Revised: $2020-10-02$ & Accepted: 2020-10-05 \\
\hline
\end{tabular}

\section{Pendahuluan}

Desa merupakan salah satu daerah otonom yang berada pada level terendah dari hierarki otonomi daerah di Indonesia (APJI, 2018). Menurut Undang-Undang Nomor 6 Tahun 2016 pada Bab 4 pasal 18 Desa mempunyai beberapa wewenang yang meliputi kewenangan di bidang penyelenggaraan pemerintah desa, pelaksanaan pembangunan desa, pembinaan kemasyarakatan desa, dan pemberdayaan masyarakat desa berdasarkan upaya masyarakat, hak asal usul, dan adat istiadat (Hanif, 2011). Dengan disahkan UU Nomor 6 Tahun 2014 tentang Desa maka dana desa mulai dikucurkan oleh pemerintah pusat pada tahun 2015 (Nugrahaningsih, 2016). Dana ini diharapkan agar 
dimanfaatkan oleh pemerintah desa untuk membiayai penyelenggaraan pemerintah, pembangunan, dan pemberdayaan masyarakat desa. Alokasi dana desa ini diharapkan mampu mengangkat daerah yang sifatnya susah untuk berkembang sehingga mampu mengejar ketertinggalan dari daerah lain (Kartika, 2015). Kebijakan dana desa, terus meningkat yakni Rp 20,67 triliun tahun 2015, Rp 46,98 triliun tahun 2016, serta masingmasing Rp 60 triliun pada tahun 2017 dan 2018 (Kementrian Dalam Negeri, 2014). Dengan begitu banyaknya dana yang dikucurkan ke desa-desa maka tentunya tanggung jawab yang dipikul oleh pemerintah desa menjadi besar pula. Oleh karena itu pemerintah desa harus bisa menerapkan prinsip akuntanbilitas dalam tata pemerintahannya, dimana semua akhir kegiatan penyelenggaraan pemerintah desa harus dapat dipertanggungjawabkan kepada masyarakat desa sesuai dengan (Kementrian Dalam Negeri, 2014).

Sesuai dengan permendagri 114/2014 pasal 29-48 maka dapat dilihat bahwa proses penyusunan Rencana Kerja Pembangunan Desa dimulai dengan proses musyawarah (Sofianto, 2017). Akan tetapi untuk saat ini proses musyawarah menjadi kurang efektif karena semakin sibuknya masyarakat dan juga kepedulian semakin rendah untuk mengikuti proses musyawarah (Bratakusuma \& Rifai, 2019).

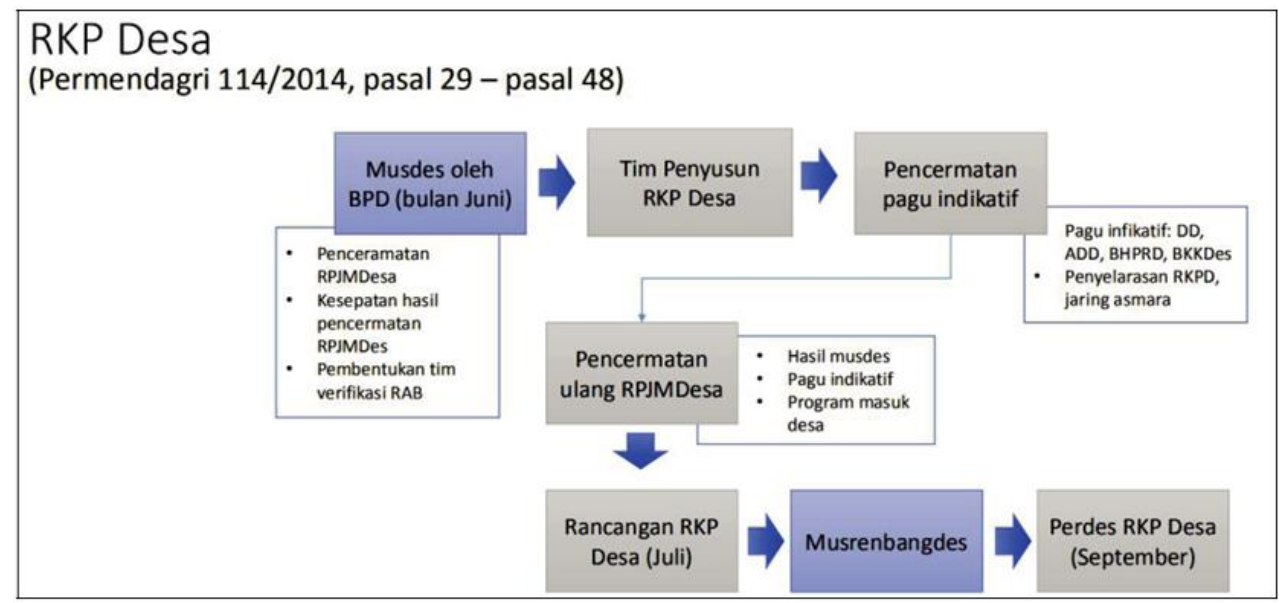

Berdasarkan laporan hasil survei Asosiasi Penyelenggara Jasa Internet Indonesia (APJII), penetrasi pengguna internet Indonesia pada tahun 2018 mencapai 171,17 juta orang dari total 264,16 juta orang penduduk Indonesia. Penetrasi pengguna internet di Indonesia tahun 2018 meningkat 10,12\% dari tahun sebelumnya. Pada tahun 2017 jumlah penetrasi pengguna internet di Indonesia adalah 143,26 juta orang dari total 262 juta orang. Tingkat penggunaan internet yang sudah sangat tinggi didalam masyarakat dapat dimanfaatkan untuk mendukung proses penganggaran diatas sehingga tujuan transparansi dan akuntabilitas dapat tercapai.

Saat ini walaupun pemerintah desa Pageraji telah menerapkan e-government namun lebih banyak untuk peningkatan pelayanan melalui penghapusan struktur birokasi yang lama dan rumit. Dalam hal ini sistem informasi lebih banyak digunakan untuk mempercepat dan otomatisasi proses. Jadi saat ini belum ada sistem informasi yang digunakan oleh pemdes yang berfokus untuk mendukung proses pengambilan keputusan.

Pakkades.id adalah salah satu sistem informasi yang ditujukan untuk menfasilitasi mekanisme penganggaran. Dalam proses penyusunan anggaran pembangunan desa, 
peran serta atau aspirasi masyarakat sangat dibutuhkan. Namun demikian seringkali terdapat kendala untuk mendapat aspirasi dari masyarakat karena mekanisme yang di jalankan sekarang hanya melalui musyawarah yang dilaksanakan satu hari, hal ini akan mempersulit jangkauan.

Dengan kegiatan pengabdian ini, tim dosen Universitas Amikom Purwokerto berusaha mengimplementasikan sistem informasi pakkades.id. Proses implementasi dimulai dengan memberikan penyuluhan, istalansi, dan konfigurasi sistem. Tahap terakhir adalah melalui penyelenggaraan pelatihan kepada pihak yang akan menggunakan aplikasinya, jadi pelatihan diikuti oleh perangkat desa, kepala desa, BPD, dan masyarakat desa.

\section{Metode}

Metode yang digunakan pada pengabdian ini adalah metode implementasi sistem yang sesuai dengan SLDC. Implementasi dimulai dengan mempersiapkan dua hal utama yaitu persiapan dan pelaksanaan. Tahap persiapan dimulai dengan menyusun konten sosialisasi, instalasi, dan konfigurasi sistem. Tahap selanjutnya pelaksanaan dilakukan dengan pelaksanaan sosialisasi melalui media sosial dan pelaksanaan pelatihan.

Tabel 1. Jadwal Kegiatan

\begin{tabular}{|c|c|c|c|c|c|c|c|c|c|c|c|c|c|}
\hline \multirow{2}{*}{ No } & \multirow{2}{*}{ Nama Kegiatan } & \multicolumn{12}{|c|}{ Bulan } \\
\hline & & 1 & 2 & 3 & 4 & 5 & 6 & 7 & 8 & 9 & 10 & 11 & 12 \\
\hline 1 & $\begin{array}{l}\text { Survei \& Studi } \\
\text { Literatur }\end{array}$ & & & & & & & & & & & & \\
\hline 2 & $\begin{array}{l}\text { Penyusunan } \\
\text { Proposal }\end{array}$ & & & & & & & & & & & & \\
\hline 3 & $\begin{array}{l}\text { Koordinasi tim } \\
\text { pengabdian } \\
\text { dengan tempat } \\
\text { pelaksana } \\
\text { pengabdian }\end{array}$ & & & & & & & & & & & & \\
\hline 4 & $\begin{array}{l}\text { Pelaksanaan } \\
\text { kegiatan } \\
\text { pengabdian }\end{array}$ & & & & & & & & & & & & \\
\hline 5 & $\begin{array}{l}\text { Evaluasi } \\
\text { kegiatan dan } \\
\text { pembuatan } \\
\text { jurnal } \\
\text { pengabdian }\end{array}$ & & & & & & & & & & & & \\
\hline 6 & $\begin{array}{l}\text { Pembuatan } \\
\text { laporan akhir }\end{array}$ & & & & & & & & & & & & \\
\hline
\end{tabular}

\section{Hasil dan Pembahasan}

Pada bagian ini diuraikan secara ringkas hasil dari pelaksanaan kegiatan pengabdian kepada masyarakat yang telah dilakukan, capaian yang telah diperoleh dan dampaknya terhadap masyarakat. 

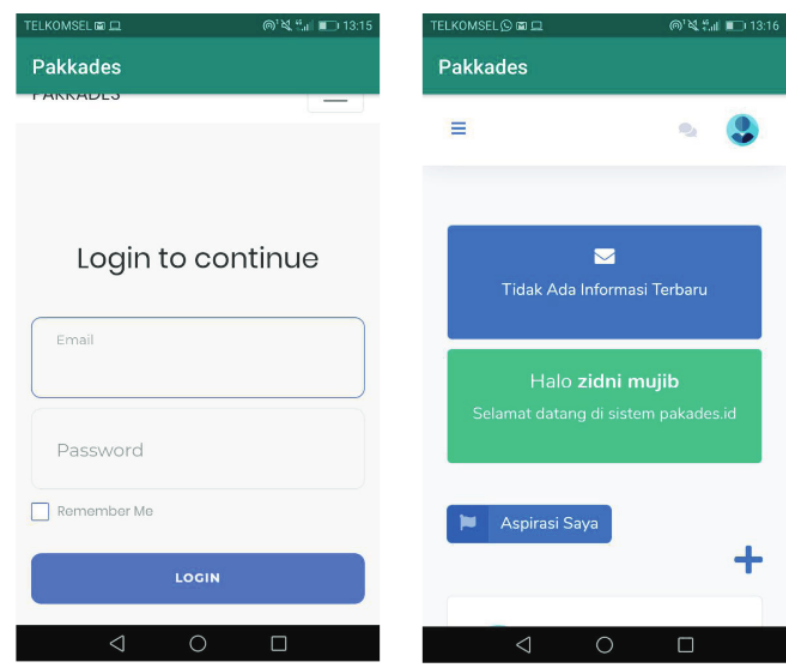

Gambar 1. Gambar Login dan Beranda Pakkades.id

Plafform web diatas digunakan oleh masyarakat. Sebelum mereka masuk ke website, masyarakat diwajibkan untuk login terlebih dahulu. Kemudian setelah berhasil akan muncul halaman utama.

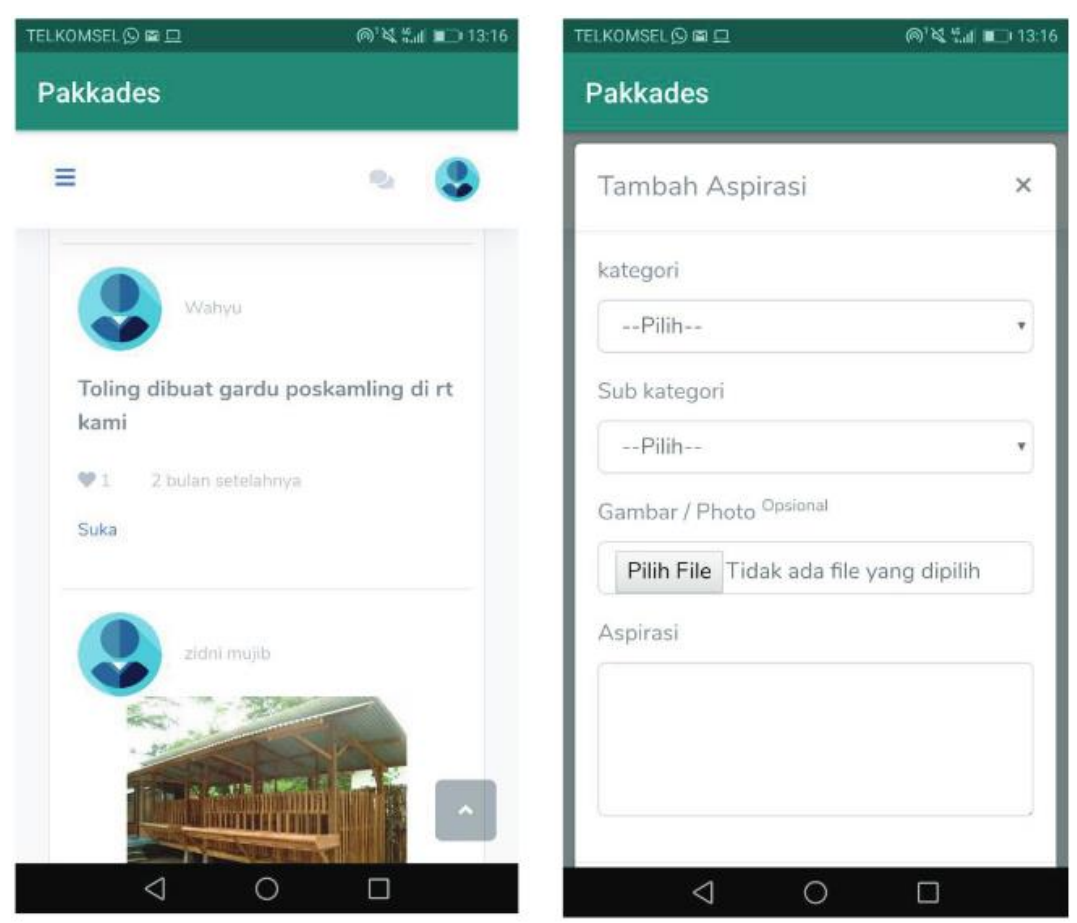

Gambar 2. Hasil Aspirasi dan Menu Tambah Aspirasi dari Masyarakat

Pada form ini masyarakat dapat melihat masukan apa saja yang diharapkan oleh masyarakat lainnnya terkait pembangunan, pengembangan, dll di Desa Pageraji. Masyarakat itu sendiri dapat menambahkan aspirasinya.

Berikut plafform web ini digunakan oleh pemerintah desa atau perangkat desa. Proses pengajuan aspirasi menjadi anggaran pembangunan desa dimulai dari memilih aspirasi yang masuk. Dari aspirasi selanjutnya dihitung menjadi RAB dan dimasukkan ke dalam aplikasi. 


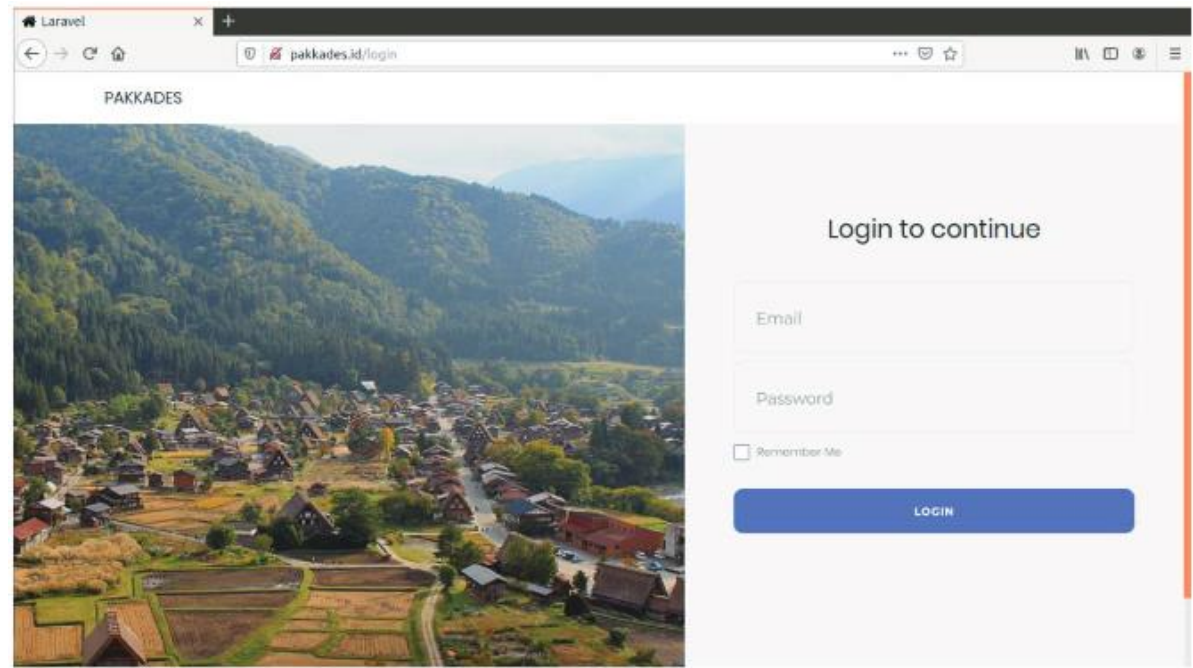

Gambar 3. Form Login Pemerintah Desa

Pada form ini pemerintah desa sebelum bisa melihat aspirasi atau usulan dari masyarakat diwajibkan terlebih dahulu login ke sistem. Dengan memasukkan email dan password yang telah dibuat.

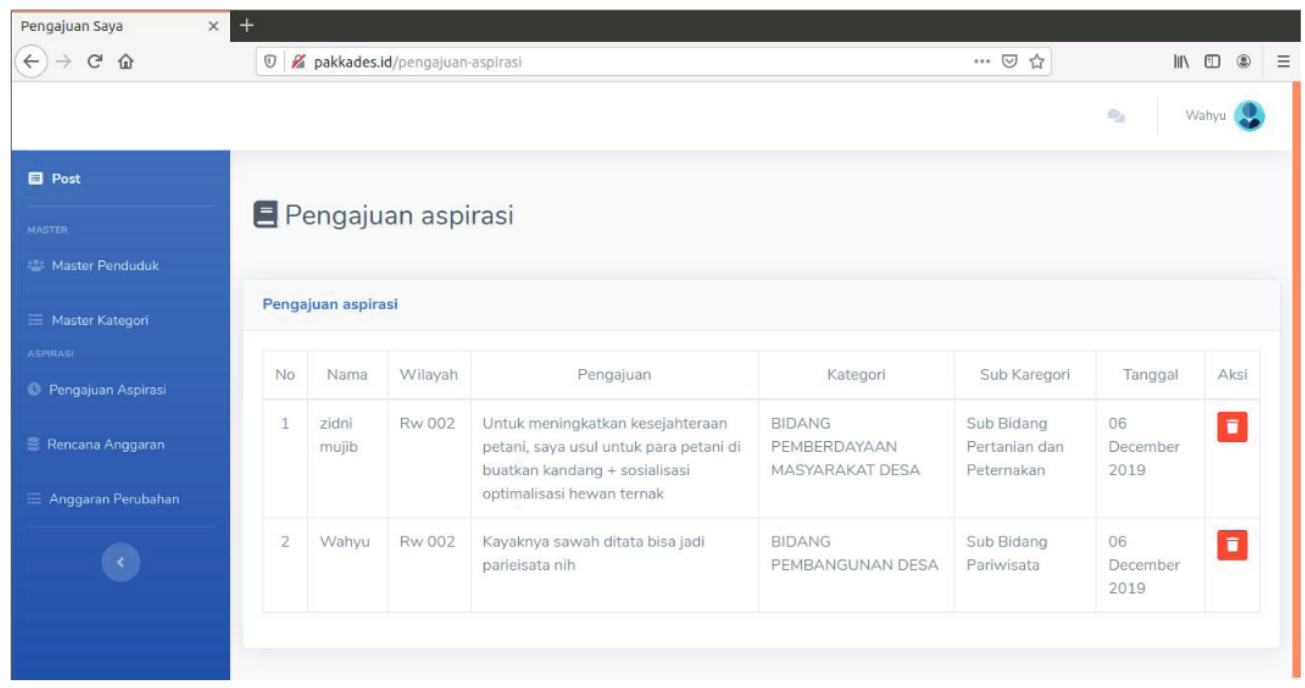

Gambar 4. Form Daftar Pengajuan Aspirasi

Pada form ini berisikan aspirasi dari masyarakat terkait pembangunan apa saja yang perlu diperbaiki, dikembangkan, atau diadakan untuk memajukan desa Pageraji. 


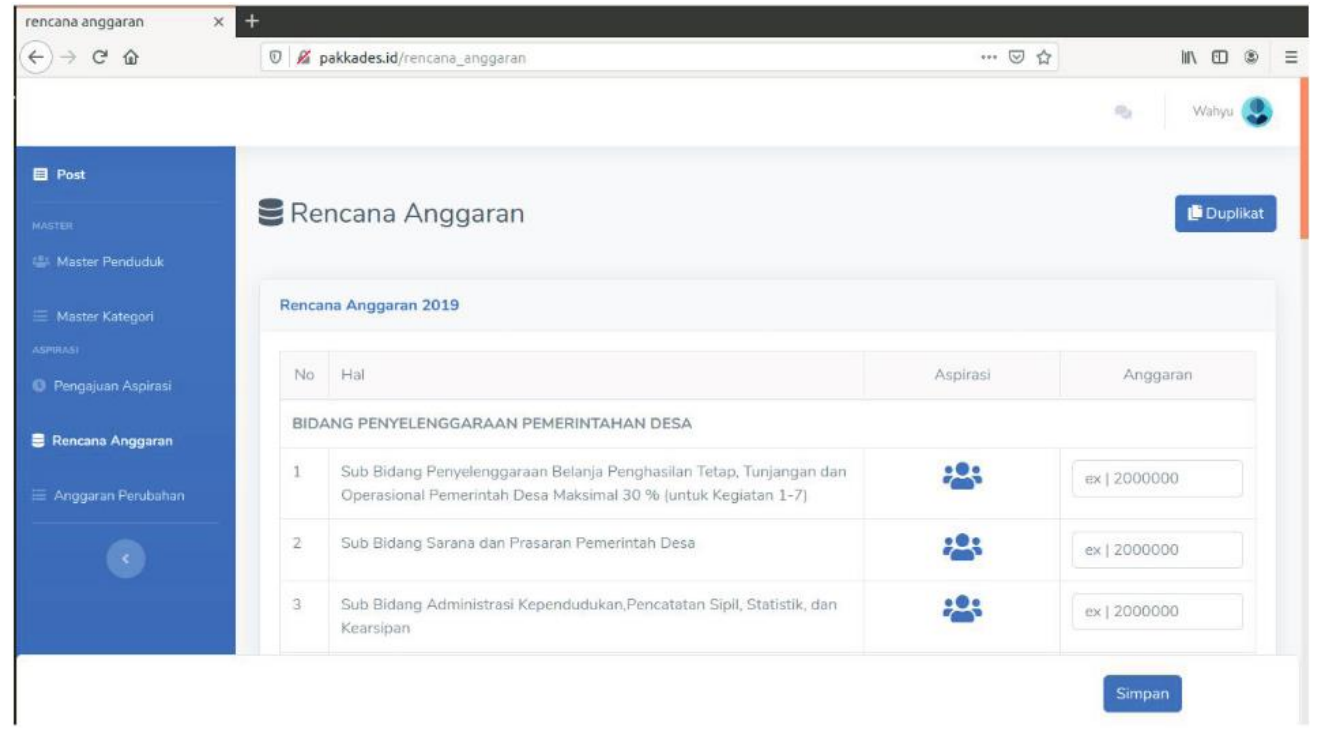

Gambar 5. Form Rencana Anggaran

Pada form ini, pemerintah desa menghitung menjadi RAB dan memasukannya ke dalam aplikasi.

\section{Kesimpulan}

Pakkades.id adalah salah satu sistem informasi yang ditujukan untuk menfasilitasi mekanisme penganggaran. Dalam proses penyusunan anggaran pembangunan desa, peran serta atau aspirasi masyarakat sangat dibutuhkan. Dengan kegiatan pengabdian ini, tim dosen Universitas Amikom Purwokerto berhasil mengimplementasikan sistem informasi pakkades.id. Proses implementasi dimulai dengan memberikan penyuluhan, istalansi, dan konfigurasi sistem. Tahap terakhir adalah melalui penyelenggaraan pelatihan kepada pihak yang akan menggunakan aplikasinya, jadi pelatihan diikuti oleh perangkat desa, kepala desa, BPD, dan masyarakat desa. Dengan adanya aplikasi Pakkades.id yang ditujukan untuk menfasilitasi mekanisme penganggaran diharapkan dapat mengefisiensikan dan mengefektifkan proses pengambilan keputusan melalui proses menangkap aspirasi masyarakat yang lebih baik. Transparansi dan akuntabilitas pemerintah desa Pageraji dapat tercapai. Dengan demikian desa Pageraji dapat lebih optimal lagi dalam segi pemerintahan, pembangunan, dan pengembangan masyarakat desa. Pada bagian ini juga perlu di ungkapkan saran-saran untuk perbaikan kegiatan ke depannya diantaranya pemerintah desa memperluas koneksi internet agar bisa dinikmati masyarakat lainnya tidak hanya di Balai Desa saja, pelatihan bisa diikuti oleh seluruh jajaran perangkat desa, mampu mengoptimalkan peran generasi muda dalam mengimplementasi aplikasi pakkades.id, dan meminta integrase data kependudukan dengan dinas terkait.

\section{Daftar Pustaka}

Asosiasi Penyelenggara Jasa Internet Indonesia. (2018). Penetrasi \& profil perilaku pengguna internet indonesia. Jakarta: Indonesia.

Hanif, N. (2011). Pertumbuhan dan penyelenggaraan pemerintah desa. Jakarta: Erlangga 
Nugrahaningsih. (2016). Optimalisasi Dana Desa Dengan Pengembangan Badan Usaha Milik Desa (BUMDes) Menuju Desa Mandiri. Jurnal Akuntansi dan Bisnis. Vol. 16 No. 1, Februari 2016: 37-45

Kartika, R. (2015). Partisipasi Masyarakat Dalam Mengelola Alokasi Dana Desa (Add) Di Desa Tegeswetan Dan Desa Jangkrikan Kecamatan Kepil Kabupaten Wonosobo. Jurnal Bina Praja: Journal of Home Affairs Governance, 4(3), 179-188. https://doi.org/10.21787/jbo.04.2012.179-188,

Kementrian Dalam Negeri. (2014). Peraturan menteri dalam negeri Republik Indonesia nomor 114 pasal 29-48 Penyusunan rencana kerja pembangunan desa. Jakarta: Indonesia.

Kementrian Dalam Negeri. (2014). Undang-Undang nomor 6 tahun 2014 tentang desa. Jakarta: Indonesia.

Sofianto, Arief. (2017). Kontribusi dana desa terhadap pembangunan dan pemberdayaan masyarakat di Kebumen dan Pekalongan. Semarang: Matra Pembaruan

Bratakusuma, T., \& Rifai, Z. (2019). Sistem Informasi Eksekutif Sebagai Pendukung Penganggaran Di Pemerintah Desa Melalui Integrasi Sistem Dengan Teknologi Web Service Dan Aplikasi Seluler (STUDI KASUS DESA DERMAJI). Jurnal Teknologi dan Terapan Bisnis, 2(2), 9-16.

www.kemenkeu.go.id/publikasi/berita/akumulasi-penyaluran-dana-desa-hingga-tahun2018-tahap-2-mencapai-rp149-31-triliun/. 